\title{
Critical basilar expansion of the sphenoidal sinus associated with a spontaneous cerebrospinal fluid fistula: the relevance of multidetector computed tomographic cisternography
}

Expansão basilar crítica do seio esfenoidal associada à fístula liquórica espontânea: a relevância da cisternotomografia computadorizada multidetectores

Antônio José da Rocha, Carlos Jorge da Silva

A 46-year-old woman presented with an intermittent nontraumatic cerebrospinal fluid (CSF) left rhinorrhea. A multidetector computed tomographic (MDCT) study was performed to investigate a CSF fistula (Figure).

The sphenoidal sinus is prone to CSF leakage, when anatomical variations occur. The basilar expansion is a posterior expansion of the sphenoidal sinus (postsellar). It is considered critical for endoscopic surgery approach and also a predisposing factor to spontaneous or posttraumatic CSF fistula when the posterior wall of the sphenoidal sinus is $\leq 2 \mathrm{~mm}$ thick $^{1}$.

Similar imaging reports in current literature are rare $\mathrm{r}^{1-4}$. Typical pattern on MDCT images, particularly after iodinated intrathecal contrast administration, reinforces its relevance to confirm the exact location of the CSF fistula for a proper surgical approach.
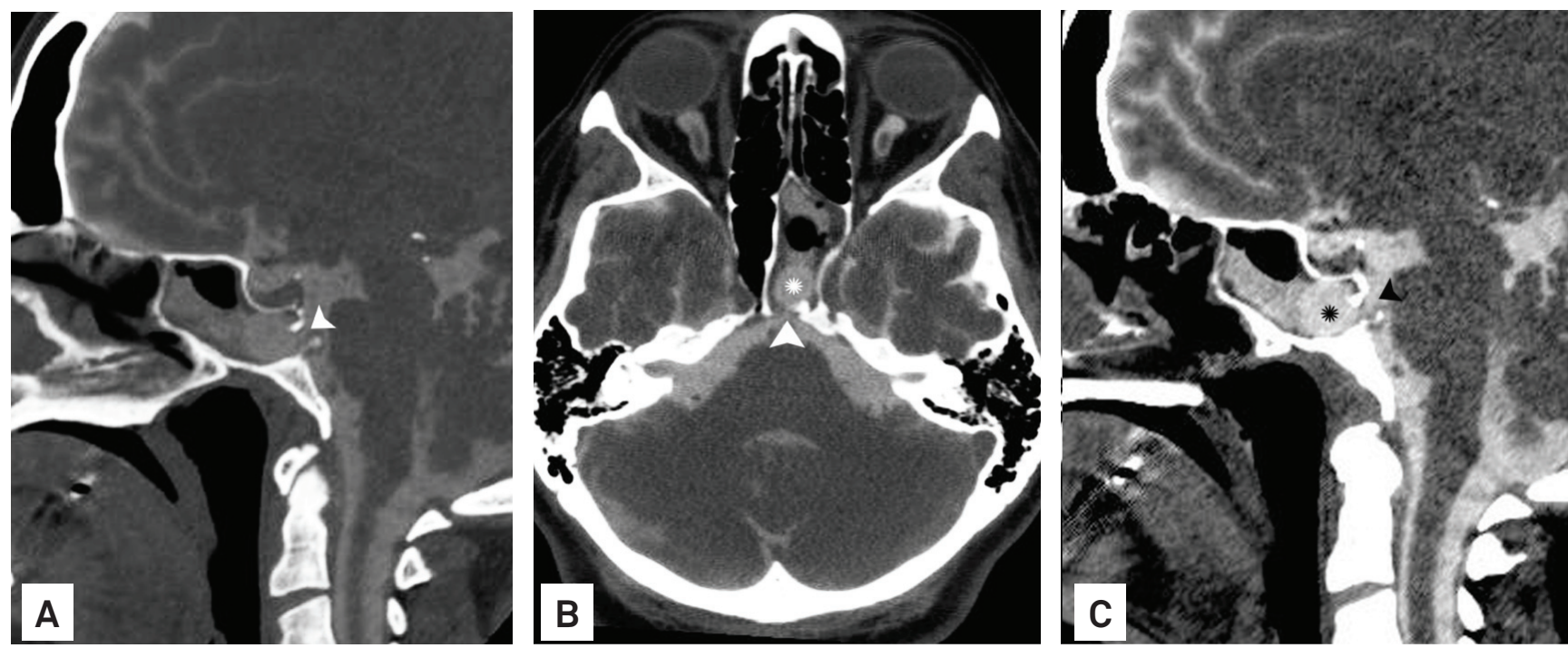

Figure. Multidetector computed tomographic images after intrathecal iodinated contrast administration. Bone window in the sagittal plane: (A) image clearly demonstrated a bone defect in a critical basilar expansion of the sphenoidal sinus (arrowhead); axial (B) and sagittal (C) planes using appropriate window confirmed spontaneous cerebrospinal fluid fistula (arrowhead) by showing contrast material filling the left sphenoidal sinus (asterisk). 


\section{References}

1. Haetinger RG, Navarro JA, Liberti EA. Basilar expansion of the human sphenoidal sinus: an integrated anatomical and computerized tomography study. Eur Radiol 2006;16:2092-2099.

2. Lockwood AH, Quencer RM, Page LK. CSF rhinorrhea from a transclival meningocele demonstrated with metrizamide CT cisternography. Case report. Neurosurgery 1980;53:553-555.
3. Akyuz M, Arslan G, Gurkanlar D, Tuncer R. CSF rhinorrhea from a transclival meningocele: a case report. Neuroimaging 2008;18: 191-193.

4. Shetty PG, Shroff MM, Fatterpekar GM, Sahani DV, Kirtane MV. A retrospective analysis of spontaneous sphenoid sinus fistula: MR and CT findings. AJNR Am J Neuroradiol 2000;21:337-342. 